\title{
Elaboração e avaliação da disciplina remota de Física 1 na UFRJ durante a pandemia de Covid-19 em 2020
}

Physics 1 at UFRJ during the Covid-19 pandemics in 2020: elaboration and evaluation of a remote course

\author{
Bruno Souza de Paula ${ }^{1}$, Camilla Codeço ${ }^{1}$, Malena Hor-Meyll ${ }^{1}$, Thereza Paiva*10 \\ ${ }^{1}$ Universidade Federal do Rio de Janeiro, Instituto de Física, Rio de Janeiro, RJ, Brasil.
}

\begin{abstract}
Recebido em 23 de dezembro de 2020. Revisado em 27 de janeiro de 2021. Aceito em 27 de janeiro de 2021.
A pandemia de COVID-19, que irrompeu globalmente no ínicio de 2020, surpreendeu o mundo e seguramente uma das área mais afetadas foi a da Educação. Universidades, escolas e até mesmo creches, entre outros, interromperam suas atividades presenciais abruptamente, marcando uma geração que testemunhou um evento que há cem anos não acontecia, desde a gripe espanhola. Educadores de todos os países foram impelidos a adotar o ensino remoto como forma de dar prosseguimento às suas atividades essenciais, num desafio sem precedentes para a grande maioria. A Universidade Federal do Rio de Janeiro, e mais especificamente, o Instituto de Física respondeu ao desafio de forma ambiciosa: não apenas migrou para o ensino remoto como aproveitou a oportunidade para colocar em prática novas metodologias de ensino ativas em uma das disciplinas com o maior contigente de alunos: Física 1. O objetivo deste artigo é detalhar como a disciplina foi re-estruturada para a forma remota e como se desenvolveu ao longo do primeiro período por meio de avaliações estatísticas de diversos aspectos incluindo pareceres dos próprios estudantes envolvidos.
\end{abstract}

Palavras-chave: Instrução por pares, Ensino remoto, Física 1.

The COVID-19 pandemic, which broke out globally in early 2020, surprised the world and surely one of the most affected areas was Education. Universities, schools and even daycare centers, among others, abruptly interrupted their face-to-face activities, marking a generation that witnessed an event that hadn't happened in a hundred years, since the Spanish flu. Educators from all countries were impelled to adopt remote education as a way to continue their essential activities, in an unprecedented challenge for the vast majority. The Universidade Federal do Rio de Janeiro, and more specifically, the Instituto de Física boldly responded to the challenge: not only did it migrate to remote education, but also took the opportunity to put into practice new active teaching methodologies active in one of the courses with the greatest contingent of students: Physics 1 . The purpose of this article is to detail how the discipline was restructured to the remote form and how it developed over the first period through statistical assessments of various aspects including opinions of the students involved.

Keywords: Peer instruction, Remote Teaching, Physics 1.

\section{Introdução}

A pandemia de Covid-19 no início de 2020, paralizando todo o planeta, obrigou a maioria dos educadores a se adaptar rapidamente e não só aprender como também adotar novas plataformas de ensino em um curtíssimo espaço de tempo. Neste artigo descrevemos a elaboração de um curso totalmente remoto incluindo a incorporação de novas tecnologias e metodologias de ensino na disciplina de Física 1 da Universidade Federal do Rio de Janeiro (UFRJ). Reportamos também o resultado de uma ampla avaliação de diferentes aspectos da disciplina, tais como, desempenho dos alunos, alcance do material preparado e a percepção dos alunos após o fim do semestre, entre outros.

A disciplina Física 1, que introduz os conceitos básicos de mecânica clássica, é oferecida semestralmente pelo Instituto de Física (IF) da UFRJ para um número

\footnotetext{
${ }^{*}$ Endereço de correspondência: therezaclpaiva@gmail.com
}

expressivo de alunos, distribuídos em curso ${ }^{1}$ do Centro de Ciências da Matemática e da Natureza (CCMN) e do Centro de Tecnologia (CT). No primeiro semestre de 2020 contávamos com 1800 alunos inscritos, que tiveram uma única semana de aula antes da interrupção causada pela pandemia. Com taxas de reprovação e evasão historicamente muito altas, conforme iremos quantificar nas próximas seções, a coordenação havia planejado, antes do surgimento da pandemia, introduzir

\footnotetext{
1 Astronomia, Ciência da Computação, Biofísica, Bacharelado em Ciências Matemáticas e da Terra, Engenharia Ambiental, Engenharia Civil, Engenharia de Alimentos, Engenharia de Bioprocessos, Engenharia de Computação e Informação, Engenharia de Controle e Automação, Engenharia de Materiais, Engenharia de Petróleo, Engenharia de Produção, Engenharia Eletrônica e de Computação, Engenharia Elétrica, Engenharia Matemática, Engenharia Mecânica, Engenharia Metalúrgica, Engenharia Naval e Oceânica, Engenharia Nuclear, Engenharia Química, Bacharelado em Física, Física Médica, Bacharelado em Matemática, Meteorologia, Nanotecnologia, Baharelado em Química, Química com Atribuições Tecnológicas e Química Industrial.
} 
em quatro turmas metodologias alternativas de aprendizagem, como sala de aula invertida [1, 2] e instrução por pares [3], que serão amplamente discutidas ao longo deste artigo. Essas turmas comporiam um projeto piloto e a comparação com as turmas regulares permitiria uma avaliação da efetividade da metodologia e contribuiriam para alertar os coordenadores dos diversos cursos atendidos pelo IF sobre a necessidade de introduzir abordagens mais modernas de ensino. $\mathrm{Na}$ verdade, a superioridade desses métodos em relação aos tradicionais, particularmente em questões conceituais, tem sido recorrentemente constatada por estudos estatisticamente rigorosos [8, 9]. Com o advento da pandemia, as aulas presenciais foram interrompidas em março e retomadas de modo totalmente remoto no chamado Período Letivo Excepcional (PLE) que ocorreu de 24 de agosto a 16 de novembro de 2020, contabilizando um semestre de 12 semanas - mais curto do que o usual de 15 semanas. Neste semestre excepcional, a coordenação disponibilizou 1650 vagas, divididas em 18 turmas. Em virtude da maioria dos onze professores alocados para a disciplina não ter nenhuma experiência prévia em ensino remoto, aproveitamos a oportunidade para fazer uma mudança drástica e ousada: oferecer ensino remoto com aprendizagem ativa em todas as turmas atendidas, utilizando o período de março a agosto para a reestruturação da disciplina e o planejamento das atividades necessárias.

Ao final do semestre procuramos extrair o máximo de informações de todas as plataformas utilizadas na disciplina, bem como a opinião dos alunos por meio de questionário. Todas as estatísticas e análises que julgamos relevantes e que constam neste artigo foram obtidas a partir destes dados.

O artigo está organizado da seguinte forma. Nas seções iniciais discutimos como a página da disciplina foi elaborada e avaliamos o quanto foi acessada pelos estudantes; descrevemos as videoaulas gravadas e analisamos as estatísticas disponíveis do canal de Youtube aberto para a disciplina. Além disto, discorremos sobre os atendimentos síncronos oferecido aos alunos: aulas com enquetes e discussão por pares e atendimento exclusivo para dúvidas ministrado por professores e monitores. As seções seguintes são dedicadas a uma extensa discussão sobre as diversas avaliações em que se baseia nosso estudo sobre o desenvolvimento da disciplina. Nas considerações finais fazemos um balanço dos pontos positivos e negativos, juntamente com sugestões para outros professores que desejem oferecer um curso remoto com aprendizagem ativa.

\section{Página da Disciplina}

Elaboramos uma página [10] para a disciplina na plataforma Wordpress que se tornou nossa principal forma de comunicação com os alunos. Esta página contém todas as informações sobre a disciplina, como cronograma, ementa, critério de aprovação, bibliografia, datas e horários das aulas síncronas e provas, entre outros. Destacamos a aba "Guia de Estudos" que, no nosso entender, foi fundamental para o acompanhamento da disciplina, cuja ementa foi dividida em seis módulos: Cinemática, Leis de Newton, Trabalho e energia, Conservação do momento linear e colisões, Rotações e momento angular e Dinâmica do corpo rígido. Para cada módulo, o Guia de Estudos especifica quais seções da bibliografia recomendada devem ser lidas, quais exercícios devem ser resolvidos e quais videoaulas gravadas pela equipe devem ser assistidas antes de cada aula síncrona. Além do Guia de Estudos, a página inclui a aba "Material de Apoio" onde os alunos podem encontrar material complementar para cada módulo, por meio de links para vídeos de demonstrações e videoaulas da UFRJ e de outras instituições, todos assistidos e selecionados por professores da equipe, num extenso trabalho de curadoria.

A Figura 11 mostra o número de visualizações da página da disciplina que escolhemos destacar. A Figura 1(a), que contém o número de acessos à pagina inicial, revela um pequeno engajamento dos alunos na primeira semana de aula presencial, antes do PLE, levando a 2627 acessos durante o mês de março. Nos meses de intervalo entre a primeira e única semana de aula e o PLE, os alunos se dispersaram, mas com o início das aulas remotas em agosto houve grande acesso às informações disponibilizadas, com mais de 30.000 acessos à página inicial em setembro. Na Fig. 1(b) mostramos o número de acessos às abas mais visualizadas. Como esperado, no início do período, houve maior busca por abas com informações sobre organização, como "Professores e Turmas" e "Cronograma". Ao longo de todo o período nota-se um expressivo número de acessos ao Guia de Estudos, comprovando que este foi de fato um recurso bastante utilizado pelos estudantes. Naturalmente, o aumento acentuado de acesso à aba "Provas" ocorreu em datas próximas à sua realização. A Fig. 1 (c) mostra a soma das visualizações do Guia de Estudos e do Material de Apoio relativo a cada módulo de conteúdo. Pode-se notar que o módulo de Cinemática foi bastante visitado em agosto, no início do semestre, enquanto o de Dinâmica do corpo rígido foi mais acessado em novembro, no fim do semestre. É clara a redução global no número de acessos ao longo do período. Como iremos discutir nas seções a seguir, isto deve-se, em parte, à evasão da disciplina.

A Figura 2 mostra um histograma com as notas dadas à pagina da disciplina, obtido a partir do questionário preenchido anonimamente pelos alunos. Em um universo de aproximadamente $20 \%$ dos alunos que responderam ao questionário (em torno de 350), nota-se que menos de $1 \%$ deixou de consultar a página da disciplina. A maioria considerou a página em geral, o Guia de Estudos e o Material de Apoio entre bom e ótimo. 

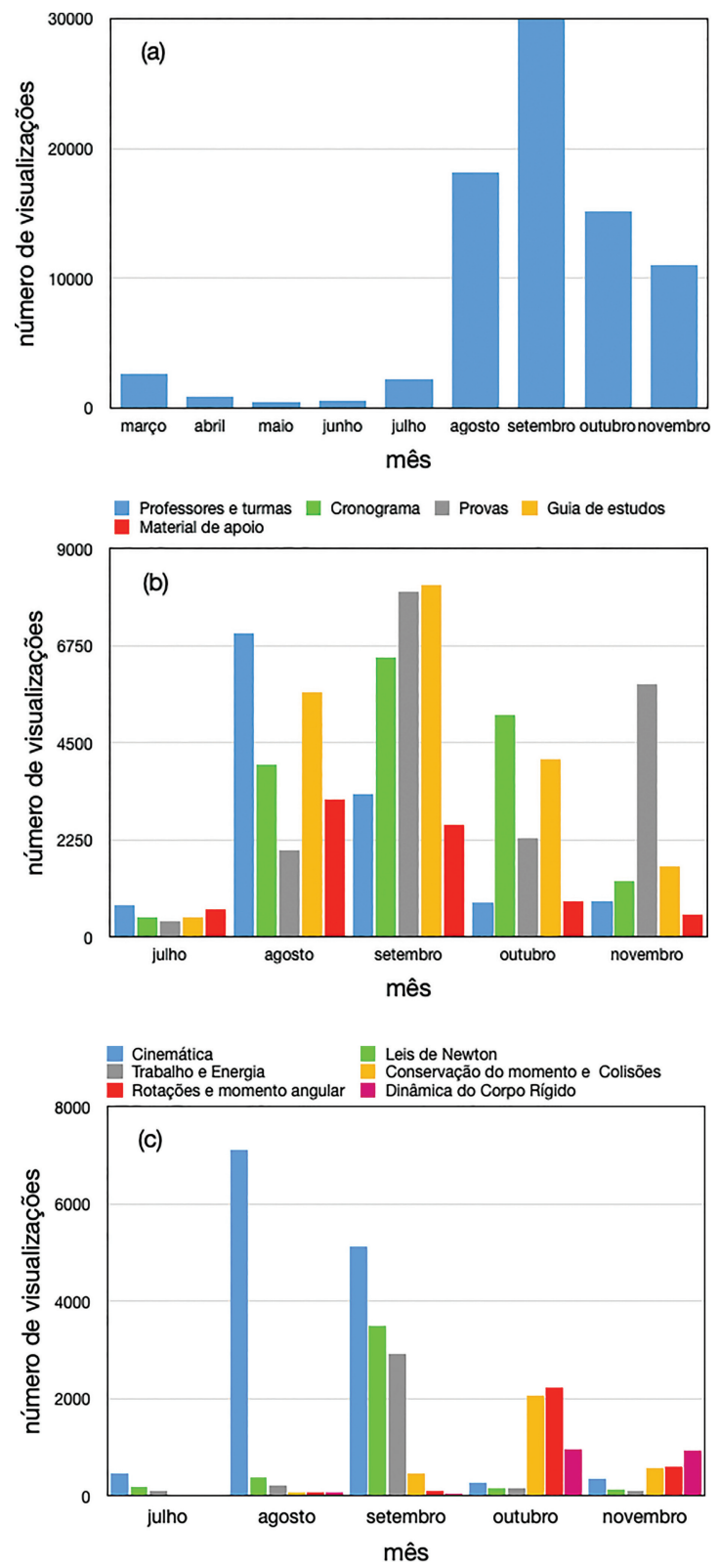

Figura 1: Número de visualizações da página da disciplina. (a) Página inicial, (b) abas de maior interesse e (c) abas dos módulos.

\section{Videoaulas e Canal de Youtube}

O canal de Youtube de Física 1 do IF [11] foi lançado em março de 2020 e até dezembro tivemos 891 inscritos, 29176 visualizações e 3337 horas assistidas. Neste canal foram postadas as videoaulas da disciplina já com foco no ensino por meio de sala de aula invertida, que pressupõe sua pré-visualização. As técnicas de sala de aula invertida e de instrução por pares e sua adaptação para o ensino remoto serão discutidas na Seção 4 A prévisualização de videoaulas como prática pedagógica se alinha à metodologia ativa de ensino, fazendo o aluno assumir o protagonismo no processo de aprendizagem. $\mathrm{O}$ aluno pode escolher a hora mais conveniente para
Página da disciplina $\square$ Guia de estudos $\square$ material de apoio

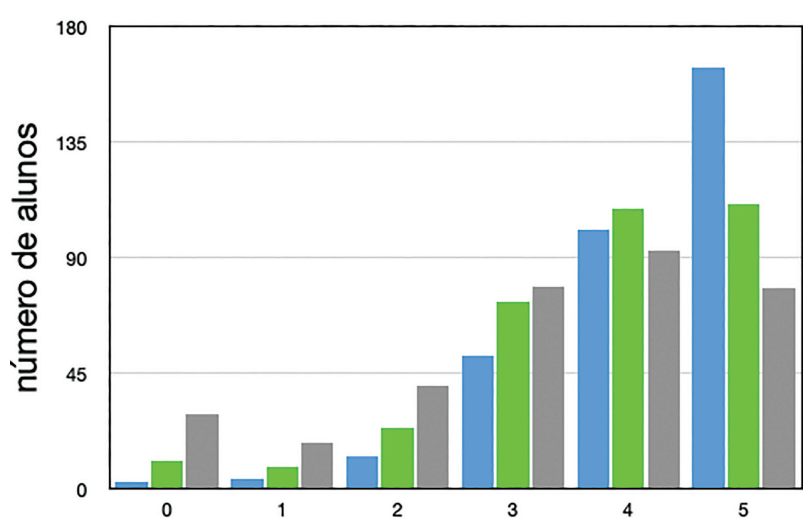

Figura 2: Avaliação dos alunos sobre as páginas da disciplina: 0 : não se aplica; 1: péssimo, 2: ruim, 3: regular, 4: bom, 5: ótimo.

assisti-las, ditar seu próprio ritmo durante a visualização, repeti-las quantas vezes julgar necessário e realizar suas anotações. As videoaulas são sucintas, com 20 minutos de duração em média, contendo apenas os conceitos fundamentais da disciplina, perguntas instigantes e problemas desafiadores. Ao todo, foram produzidas 21 videoaulas abrangendo os seis módulos da disciplina, assim distribuídas: Cinemática (aulas 1 a 5), Leis de Newton (aulas 6 a 9), Trabalho e energia (aulas 10 a 12), Conservação do momento e colisões (aulas 13 a 16), Rotações e momento angular (aulas 17 a 19) e Dinâmica do corpo rígido (aulas 20 e 21). Esta distribuição correspondeu a uma carga horária de cerca de duas videoaulas por semana.

A partir do canal do Youtube é possível extrair dados que permitem uma análise estatística de diagnóstico. Na Figura 3 apresentamos dados relativos a cada uma das 21 videoaulas. O número de visualizações está ilustrado na Figura 3(a). Podemos observar um decréscimo já a partir da segunda e que permanece no decorrer da disciplina, ficando inferior a 1250 visualizações da sétima até à vigésima primeira videoaula. $O$ decréscimo nas visualizações tem origem em diferentes causas, sendo a mais evidente, independentemente do formato adotado presencial ou remoto - a desistência da disciplina por parte dos alunos, que no PLE contabilizou 27\%. Consideramos como desistentes, os alunos que trancaram a disciplina somados aos que a abandonaram, este últimos caracterizados pela reprovação com média zero. Por ser um semestre de caráter excepcional, o trancamento foi permitido durante todo o PLE. O percentual do decréscimo de visualizações das videoaulas foi em torno de $80 \%$. Logo, outros fatores, além da desistência, também influenciaram. Não podemos desconsiderar que alguns alunos podem ter optado por estudar a partir de outros meios ou por videoaulas de outras instituições, que foram disponibilizadas como material de apoio na página da disciplina. Cabe destacar ainda que as primeiras videoaulas estão disponíveis no canal há mais tempo, 

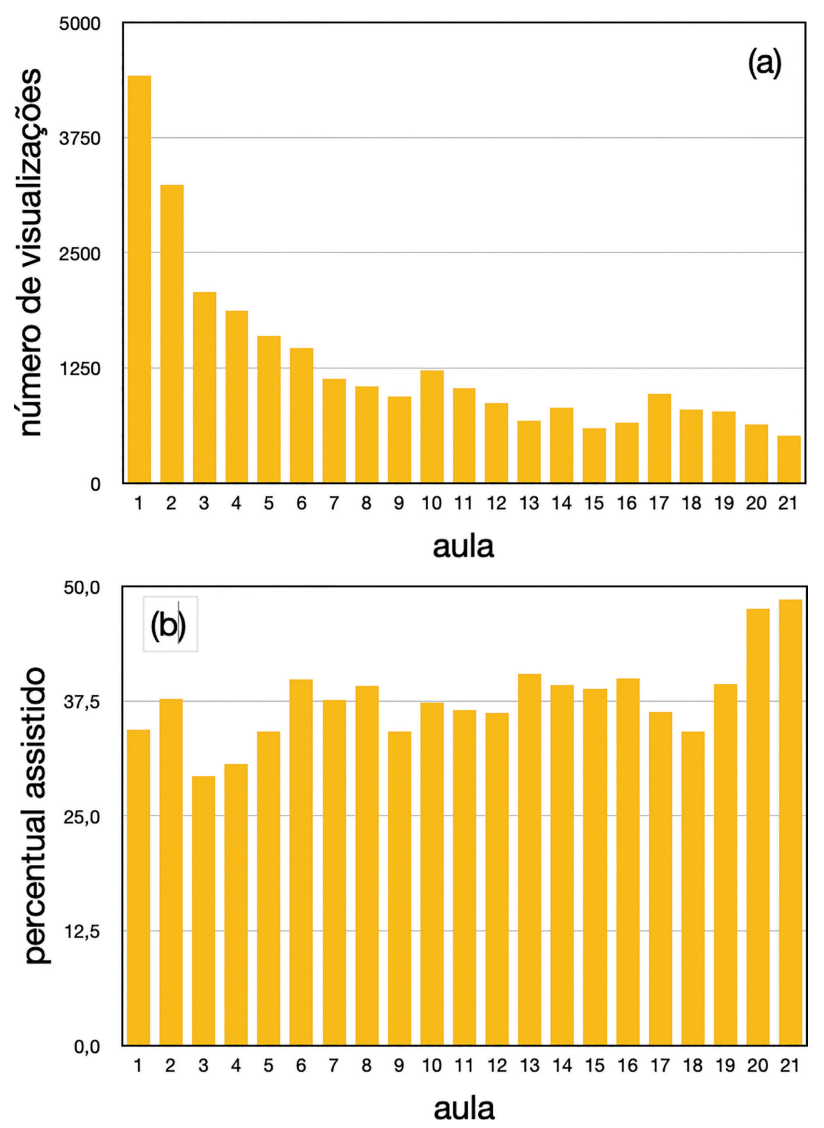

Figura 3: Dados relativos às videoaulas individuais. (a) Número de visualizações e (b) percentual médio do tempo assistido.

o que contribui para um maior número de visualizações por indivíduos não matriculados na disciplina.

Na Figura 3(b) apresentamos o percentual médio do tempo assistido em relação ao tempo total de cada videoaula, em torno de $20 \mathrm{~min}$, como já mencionado. Comparando este resultado com o anterior, é interessante notar que, embora as visualizações tenham decaído ao longo do semestre, o percentual do tempo assistido manteve-se razoavelmente constante em $37 \%$, o que corresponde em termos absolutos a aproximadamente 7,5 min. Este dado confirma uma tese já defendida na literatura [12, 13] de que as videoaulas devem ser concisas o suficiente para prender a atenção do aluno até o final.

Podemos observar que as videoaulas 3 e 4 , que correspondem aos tópicos de Vetores e Cinemática em 2 e 3 dimensões, apresentam os menores percentuais. Ainda que sejam assuntos onde os alunos encontram dificuldades, são estudados no ensino médio. A familiaridade com o tema pode contribuir para o aluno acreditar que domina os conceitos. Embora as videoaulas 1 e 2 também abordem cinemática, ressaltamos que a matemática utilizada é mais complexa, apresentando os conceitos de derivada e integral.

$\mathrm{Na}$ Figura 4 apresentamos dados percentuais de participação na disciplina por gênero. É amplamente

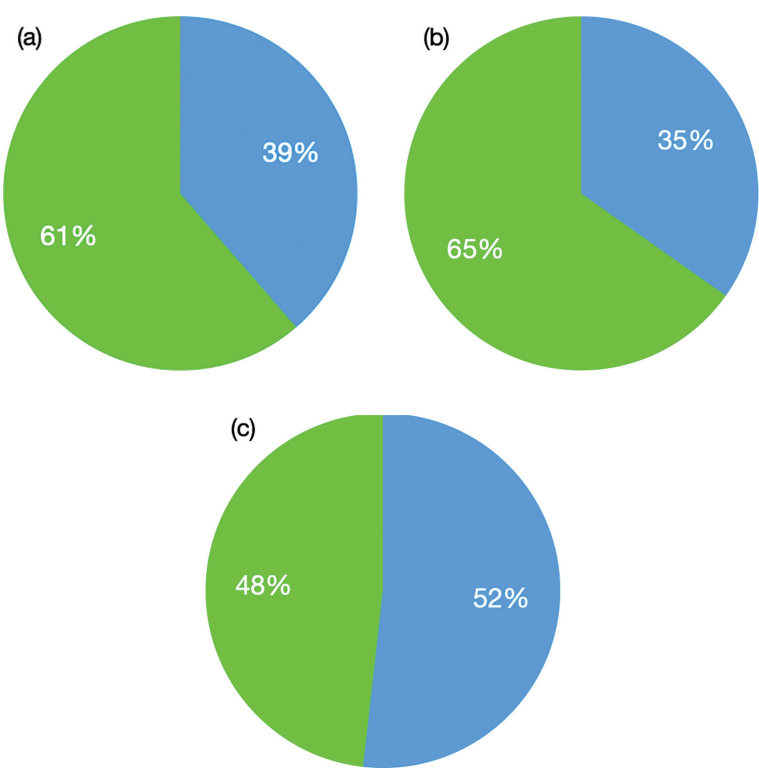

Figura 4: Dados percentuais de participação na disciplina por gênero. (a) Inscrições na disciplina, (b) visualizações de videoaulas e (c) horas assistidas. Em verde homens e em azul mulheres.

reconhecido o desbalanço de gênero em cursos das áreas exatas e tecnológicas e nesta disciplina não foi diferente: houve $39 \%$ de mulheres inscritas, como ilustra a Figura 4(a). Este é um valor médio entre as alunas dos diferentes cursos (diferentes engenharias e outros) e há grandes variações entre eles. A distribuição de visualização entre os gêneros acompanha este percentual, conforme mostra a Fig. 4(b). Curiosamente, o percentual de horas assistidas é maior entre as mulheres, como mostra a Fig. 4(c).

A Figura 5, apresenta dados acerca dos dispositivos eletrônicos utilizados para assistir às videoaulas. O número de visualizações por dispositivo é apresentado na Figura 5(a), onde podemos observar que o computador e o celular foram os meios mais utilizados e, mais raramente, tablets, TVs e consoles de jogo. Seria interessante investigar se há correlação entre o perfil socioeconômico dos alunos e o meio utilizado para assistir aos vídeos. Por ser totalmente anônimo, pretendemos incluir futuramente no questionário de avaliação preenchido pelos alunos, um tópico (opcional) sobre esse dado. Esta informação pode levar a conclusões importantes acerca do papel do ensino remoto na redução de desigualdades sociais, como será discutido na última seção. A Figura 5(b) apresenta a duração média assistida das videoaulas em função do meio utilizado. O computador e o celular, embora tenham sido os equipamentos mais utilizados, apresentam um tempo assistido inferior a 7 minutos, em contraste com os meios pouco utilizados que apresentam tempos superiores a 7 minutos, com destaque para a TV. Cabe ressaltar que mesmo considerando o meio com maior duração assistida, o tempo médio corresponde a $10 \mathrm{~min}$. Esse 

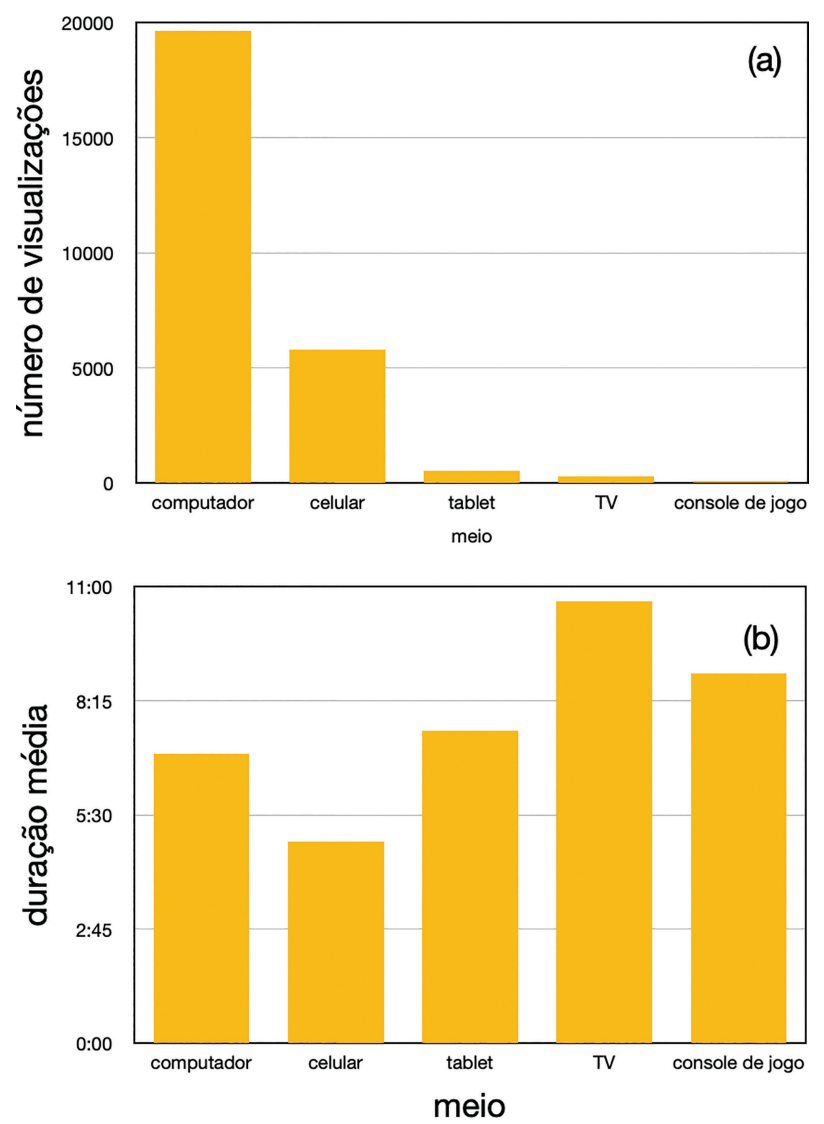

Figura 5: Dados relativos aos meios utilizados para assistir às videoaulas. (a) Número de visualizações por dispositivo e (b) tempo médio em cada meio.

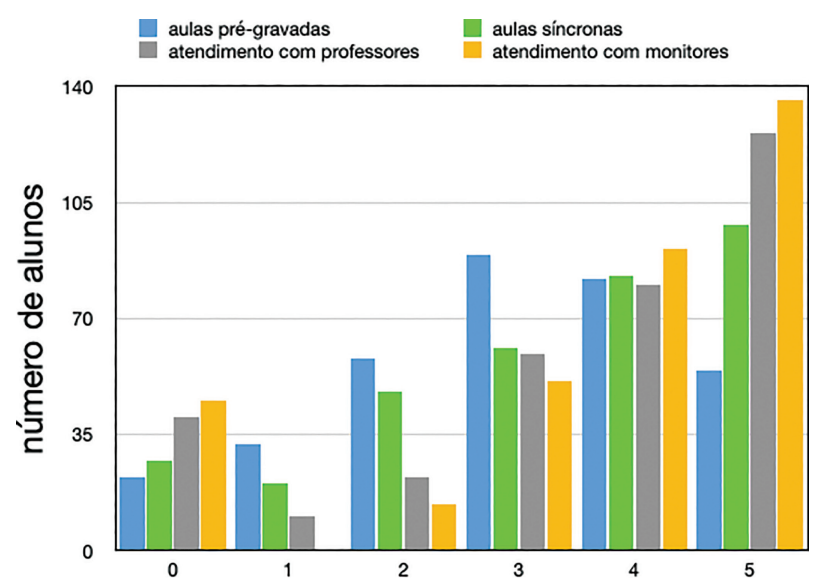

Figura 6: Avaliação dos alunos sobre as aulas pré-gravadas, aulas síncronas, atendimento síncrono com professores e monitores. 0: não se aplica, 1: péssimo, 2: ruim, 3: regular, 4: bom, 5: ótimo.

resultado confirma nossa ponderação anterior de que as videoaulas devem ser breves, tendo maior probabilidade de serem assistidas até o final, e consequentemente, resultando em maior eficiência de aprendizado.

$\mathrm{Na}$ Figura 6 apresentamos o resultado do questionário preenchido pelos alunos com respeito aos pontos discutidos nesta seção. Podemos observar que $65 \%$ dos alunos avaliaram positivamente as aulas pré-gravadas (videoaulas) com conceitos entre regular, bom e ótimo. Cerca de $28 \%$ dos alunos as classificaram como ruim ou péssima. A principal reclamação apresentada foi a ausência de videoaulas com resolução de exercícios. $7 \%$ dos alunos consultados classificaram como "não se aplica", ou seja, preferiram não avaliar as videoaulas, provavelmente, porque não se utilizaram delas para estudo.

\section{Atendimento aos Alunos}

Durante o PLE foi oferecido atendimento aos alunos em três formatos remotos na plataforma $Z$ oom ${ }^{2}$, aulas síncronas, atendimento com professores e com monitores - alunos veteranos já aprovados na disciplina. Cada turma contava com duas aulas síncronas de uma hora de duração por semana. Com a redução do número de alunos após a primeira prova, reunimos pares de turmas oferecendo aulas de uma hora e meia de duração. Nestas aulas diagnosticávamos o grau de compreensão dos estudantes e aplicávamos o método de instrução por pares. Em sua versão original, esta metodologia consiste, em oposição à tradicional aula expositiva, na apresentação aos alunos de questões conceitualmente relevantes na sala de aula. Os alunos são instados a discutir as questões divididos em grupos e, sem a intervenção do professor, chegar a uma conclusão sobre a resposta. Depois de apresentados os resultados dos diversos grupos, o professor então avalia o percentual de acertos e em função disto decide que ação tomar: interferir e dar explicações caso o percentual de acerto seja muito baixo ou apresentar uma nova questão.

As videoaulas apresentavam o conteúdo para os alunos e davam suporte para as aulas síncronas. Seguindo a metodologia de sala de aula invertida, era solicitado que os alunos assistissem as videoaulas antes de participarem das aulas síncronas correspondentes. Mais especificamente, na técnica da sala de aula invertida o professor passa atividades de leitura ou vídeos a serem realizadas previamente, usando o espaço de aula propriamente dito para tirar dúvidas e interagir com os alunos. Desta forma, o foco da aula passa a ser "aprender" e não "ensinar" conforme a excelente colocação da Referência [2].

A Figura 7 apresenta dados das aulas síncronas relacionados aos módulos da disciplina. O número de participantes das aulas síncronas correspondente a cada módulo é apresentado na Figura 7(a). A partir da aula de Trabalho e energia é possível observar uma queda no número de participantes que se mantém até o módulo de Rotações e momento angular. A queda é de aproximadamente $41 \%$ e os fatores que influenciaram foram a desistência da disciplina, que corresponde a $27 \%$ e o fato de alguns alunos pararem de assistir às aulas

\footnotetext{
2 https://zoom.us/
} 

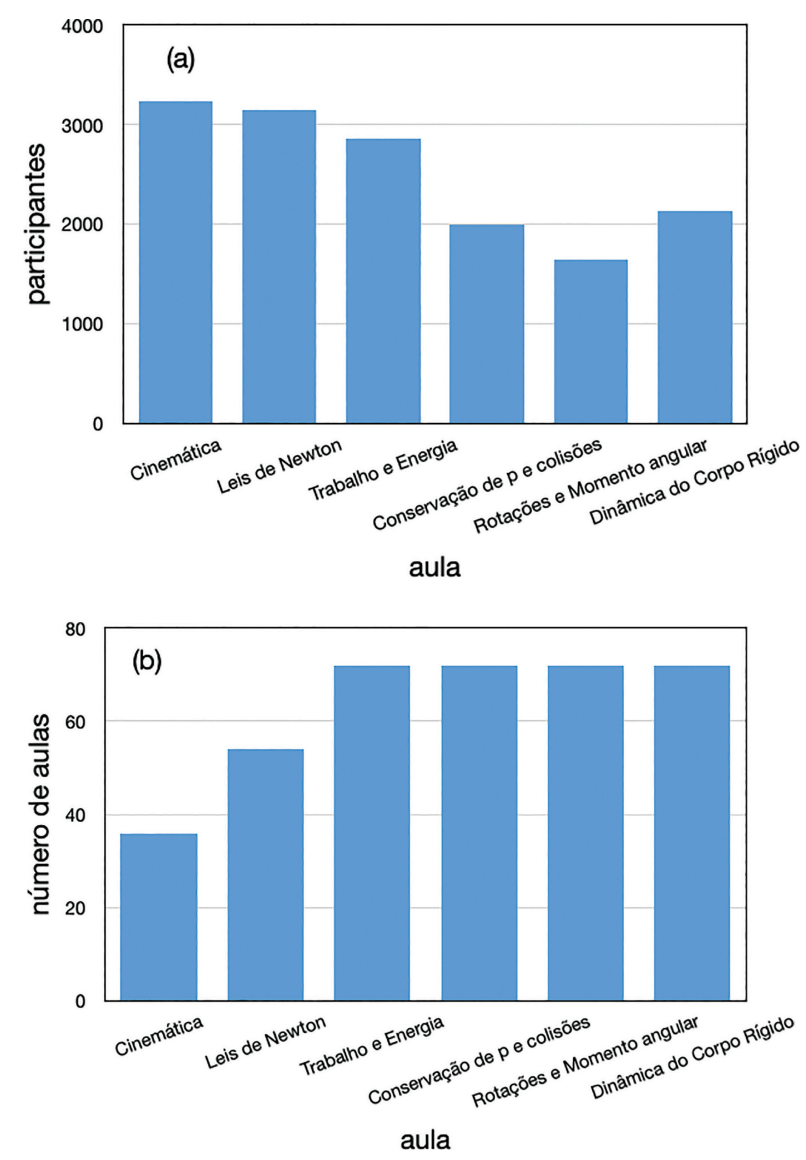

Figura 7: Dados das aulas síncronas por módulos da disciplina. (a) Número de participantes e (b) número total de aulas síncronas.

síncronas, embora não tenham desistido da disciplina. A Figura 7(b) apresenta o número de aulas síncronas de todas as turmas por módulo.

Para testar a compreensão dos alunos durante as aulas síncronas foram propostos problemas, a partir da recurso "enquete" (quiz) da plataforma Zoom, com o tema de acordo com a videoaula correspondente. Este recurso permite que os alunos individualmente marquem sua resposta a uma questão apresentada e imediatamente retorna ao professor a porcentagem de acertos e erros e, por exclusão, de omissões. $\mathrm{O}$ uso de enquetes promove não apenas um dinamismo à aula, engajando os estudantes, mas sobretudo viabiliza um rápido diagnóstico do grau de entendimento dos conceitos testados. A partir do resultado da enquete os professores avaliavam qual instrumento pedagógico se faria mais apropriado: discussão guiada pelo professor, caso a porcentagem de acerto fosse inferior a $30 \%$ ou instrução por pares, caso a porcentagem de acerto estivesse entre 30\% e 70\%. Após a discussão pelos alunos, a questão era reapresentada em uma nova enquete. Com o percentual de acerto superior a $70 \%$ uma breve discussão era feita por parte do professor e uma nova questão era apresentada.

Para aplicar a discussão por pares, utilizávamos o recurso "divisão por salas" (breakout rooms) do Zoom, que possibilita a criação de vários espaços virtuais (salas) que não têm comunicação entre si. Nas diversas salas virtuais, um grupo pequeno de alunos discutiam a questão apresentada, com possibilidade de utilizar um quadro branco virtual e podiam solicitar ajuda ao professor, se necessário. Por sua vez, o professor podia navegar livremente entre as várias salas. Após um certo tempo, estabelecido pelo professor, todos retornavam à sala principal. A composição de alunos nas salas pode se dar de forma aleatória ou preestabelecida, o que se revelou bastante conveniente, pois quando observávamos que uma determinada sala era composta por alunos que tinham um bom entendimento da matéria, podíamos distribui-los nas salas de outros que apresentavam maiores dificuldades. Nas aulas síncronas com duração de uma hora, o tempo que os alunos permaneciam nas salas virtuais era em torno de 4 minutos. Com o aumento da duração das aulas síncronas, esse tempo passou para cerca de 7 minutos, que avaliamos como ideal. Pôde-se observar que o número de acertos aumentava expressivamente após a discussão por pares. Em alguns poucos casos o número de acertos, após a discussão por pares, continuava inferior a $70 \%$ o que implicava numa segunda divisão por salas.

Complementando a metodologia de sala de aula invertida, toda semana eram disponibilizados diversos horários de atendimentos síncronos de 40 minutos com professores e monitores exclusivamente para tirar dúvidas das videoaulas, das leituras e dos exercícios propostos.

A avaliação dos alunos em relação às aulas síncronas por meio do questionário, apresentada na Figura 6. mostra que $52 \%$ dos alunos as classificaram entre boa e ótima. Este é um resultado positivo indicando que a estrutura das aulas remotas baseada na resolução de exercícios via instrução por pares teve boa aceitação e adaptação por parte dos alunos. Cerca de 19\% dos alunos classificaram as aulas síncronas como regular, 16\% como ruim e $5 \%$ como péssima. As principais reclamações apresentadas nas avaliações ruim e péssima foram a curta duração da aula síncrona (inicialmente de uma hora) e a ausência de aulas expositivas. Isso revela que uma pequena parcela dos estudantes não gostou ou não se adaptou à dinâmica da sala de aula invertida. $8 \%$ dos alunos avaliaram como "não se aplica", indicando que não a frequentaram.

Com relação ao atendimento oferecido pelos professores, $62 \%$ dos alunos o avaliaram entre bom e ótimo, $19 \%$ como regular, $5 \%$ como ruim e $2 \%$ como péssimo. Não foi apresentada nenhuma reclamação específica dos alunos em relação ao atendimento com os professores. Finalmente, $12 \%$ dos alunos marcaram a opção "não se aplica", ou seja, não buscaram o atendimento.

Com relação ao atendimento dos monitores, $66 \%$ dos alunos o avaliaram entre bom e ótimo, $16 \%$ como regular e apenas 3\% como ruim. Vale destacar que, em termos percentuais, ambos os atendimentos foram avaliados positivamente pelos estudantes. Apenas $15 \%$ 
o classificaram como "não se aplica", mostrando que a maioria dos alunos valoriza e utiliza o espaço fora do horário de aula para tirar suas dúvidas. Arriscamos dizer que a aprovação maior do atendimento com monitores advém do fato de provavelmente se sentirem mais à vontade para tirar dúvidas com colegas mais adiantados do curso do que com professores, o que se coaduna com os princípios da instrução por pares.

\section{Provas, Questionários e Listas}

Desde que passou a ter o atual formato de disciplina unificada para todas as turmas do CCMN e do CT, a avaliação da disciplina de Física I consiste essencialmente em provas idênticas (salvo diferenças na sequência de questões e opções), presenciais e realizadas simultaneamente por alunos de todos os cursos. Esse formato, não pôde ser mantido no ensino remoto e a avaliação representou um dos grandes desafios do PLE.

Duas grandes preocupações nortearam o esquema de avaliação remota: manter os alunos estudando durante todo o período - especialmente difícil no PLE devido à falta de obrigatoriedade em assistir as aulas síncronas - e evitar que houvesse comunicação entre os alunos durante a realização de tarefas individuais.

A plataforma escolhida para a realização de todas as avaliações remotas foi baseada no "Moodle" (Modular Object-Oriented Dynamic Learning Environment), um programa de acesso livre de apoio ao ensino virtual. Dentre as inúmeras variantes baseadas nesta plataforma, optamos pelo "Polimoodle", desenvolvido pela Escola Politécnica da UFRJ, por sua maior robustez. Para ter acesso à plataforma é necessário ter um e-mail institucional da UFRJ e fazer a conexão através de conta pessoal individual.

Nos anos recentes, apesar do maior peso da avaliação consistir nas provas presenciais mencionadas anteriormente, já vinham sendo adotados alguns questionários opcionais consistindo de problemas objetivos de múltipla escolha com cobrança parcial de conteúdo. O objetivo destes questionários era evitar o tradicional acúmulo de matéria às vésperas das provas.

A experiência dos questionários foi aproveitada e mantida a estrutura de composição da média, com duas provas, que compunham a maior parte da nota, sem contabilizar a prova final, só realizada por alunos que não alcançavam a média necessária para passar direto, como será detalhado a seguir. No PLE, os questionários intermediários foram mantidos, com seu peso na média aumentado, como forma de incentivar os alunos a estarem sempre estudando, e se tornaram obrigatórios, face à curtíssima duração do semestre.

Uma dificuldade adicional do ensino remoto é estimular a interação entre os estudantes de uma mesma turma. O estudo em conjunto facilita uma melhor apreensão do conteúdo e desempenha um papel importante de aspecto psicológico ao fazer os alunos se sentirem parte de um grupo. Esse contato se inicia naturalmente nas aulas presenciais, mas no período remoto sentimos necessidade de criar um mecanismo para tal fim. Com este objetivo em mente, introduzimos listas de exercícios para os alunos realizarem em pequenos grupos.

Na primeira parte da disciplina, os denominados Questionários Online (QO) e Listas em Grupo (LG) foram intercalados, após os quais foi a realizada a Prova 1 (P1). A nota parcial relativa a estas atividades foi denominada $\mathrm{N} 1$ e determinada da seguinte forma:

$$
N 1=0,1 \times \frac{L G 1+L G 2}{2}+0,2 \times \frac{Q O 1+Q O 2}{2}+0,7 \times P 1
$$

Na segunda metade da disciplina, propusemos apenas os questionários, por motivos a serem discutidos na subseção 5.1. e a Prova 2 (P2). Estas tarefas constituíram a nota parcial 2 (N2), calculada como:

$$
N 2=0,3 \times \frac{Q O 3+Q O 4}{2}+0,7 \times P 2
$$

A composição da denominada da Média Parcial (MP), cujo resultado podia levar à aprovação ou reprovação direta ou à necessidade de realizar uma Prova Final $(\mathrm{PF})$, seguiu os seguintes critérios:

$$
\begin{array}{r}
\mathrm{MP}=(N 1+N 2) / 2 \\
\mathrm{MP} \geq 6,0 \Rightarrow \text { Aprovado } \\
\mathrm{MP}<3,0 \Rightarrow \text { Reprovado } \\
3,0 \leq \mathrm{MP}<6,0 \Rightarrow \mathrm{PF}
\end{array}
$$

Os alunos que atenderam aos dois primeiros critérios concluíram a disciplina com média final igual à MP. Aqueles que se situaram no terceiro critério e realizaram a $\mathrm{PF}$, tiveram a média final $(\mathrm{MF})$ calculada da seguinte forma:

$$
M F=\frac{N 1+N 2+P F}{3}
$$

Alunos com $M F \geq 5,0$ foram aprovados e os demais reprovados.

\subsection{Listas em grupo}

Os problemas para serem resolvidos em grupo, de no mínimo três e no máximo cinco componentes, de forma discursiva e à mão apresentavam uma complexidade maior que àqueles apresentados nas enquetes, questionários e provas, de modo a fomentar ao máximo a discussão entre os alunos. Apenas um dos componentes enviava a resolução dos problemas através do Polimoodle, de modo que alunos do mesmo grupo compartilham necessariamente a mesma nota. Os monitores, sob a supervisão dos professores ficaram encarregados de corrigir as listas.

Evidentemente, em um universo de mais de 1600 alunos, as opiniões a respeito de qualquer uma das características da disciplina tendem a ser muito díspares. 


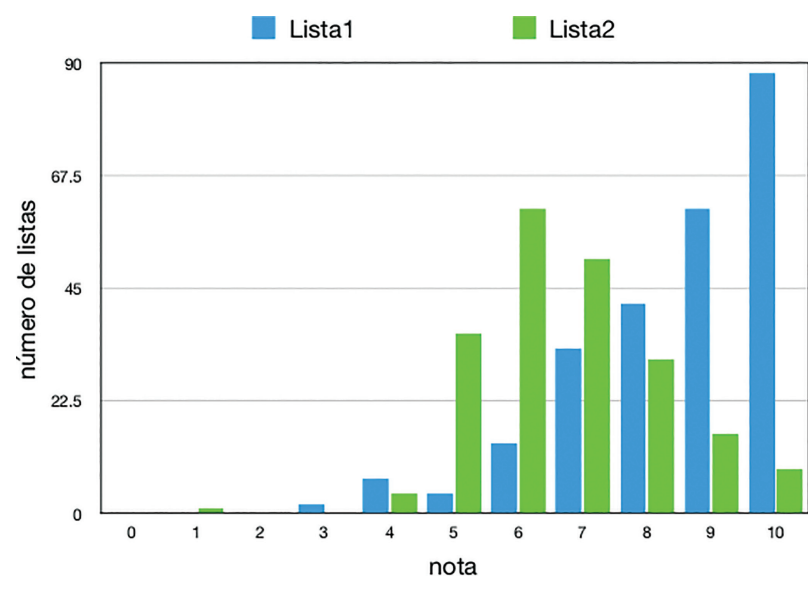

Figura 8: Histogramas com as notas das listas em grupo.

Todavia, houve um número considerável de reclamações de estudantes alegando que não conheciam outros alunos da turma para formar grupos (o fato de as Listas em Grupo terem sido pior avaliadas pelos estudantes do que os questionários e provas, como mostra a Figura 13. é um indicativo desse tipo de insatisfação). Dado o formato unificado da disciplina, que dá liberdade aos estudantes para se inscreverem em qualquer turma, e o número expressivo de calouros, essas reclamações foram consideradas e as LGs foram interrompidas na segunda metade da disciplina. Retornaremos a este ponto na última seção.

As listas em grupo LG1 e LG2 versaram sobre dois temas, respectivamente: Cinemática em 1 dimensão e aplicações das Leis de Newton e as notas obtida pelos estudandes estão mostradas na Figura 8 As médias da LG1 e da LG2 foram 8,2 e 6,4 enquanto o número de listas entregues foi de 251 e 199, respectivamente. Pode-se observar claramente um melhor desempenho na LG1. A ausência do conceito de vetor, uma das grandes dificuldades dos alunos em Física 1, e o fato de ter sido a primeira de todas as tarefas da disciplina, provavelmente contribuíram para este resultado.

Embora seja questionável a comparação do nível de complexidade de listas de exercícios que versam sobre diferentes assuntos, a disparidade de notas no gráfico parece indicar que a LG2 apresentou mais dificuldade para os alunos.

\subsection{Questionários online}

Os questionários continham dez problemas de múltipla escolha e ficavam disponíveis no Polimoodle durante quatro dias, sempre após a última aula síncrona sobre o assunto correspondente. A despeito dos quatro dias, uma vez iniciado, os alunos tinham doze horas corridas para finalizá-lo.

O objetivo de um longo período de horas era permitir que os estudantes revisassem parte do conteúdo em caso de dúvida em alguma questão, mas pressupondo que já

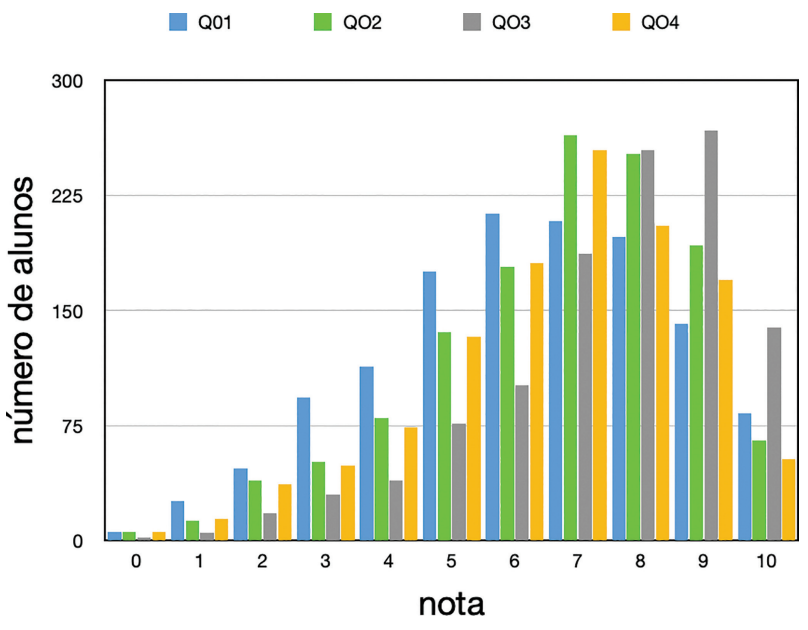

Figura 9: Histogramas com a distribuição de notas dos quatro questionários online.

tivessem realizado a maior parte do estudo antes de iniciar. Os QOs eram elaborados a partir de bancos de questões por tópicos, de modo que cada aluno fosse apresentado a um conjunto distinto de problemas.

Durante o PLE foram propostos quatro QOs, dois antes da $\mathrm{P} 1$ e dois entre a P1 e a P2, acompanhando o andamento da disciplina. Os assuntos abordados nos questionátrios foram: QO1 - Cinemática 2 e 3D e Leis de Newton Conceitual; QO2 - Trabalho e Energia (Trabalho de uma força, Trabalho e energia cinética, Trabalho e energia com forças variáveis); QO3 - Conservação do Momento e Colisões e QO4 - Rotações e Momento Angular.

Na Figura 9 está ilustrada a distribuição de notas dos alunos nos quatro questionários propostos. As médias obtidas nos questionários foram QO1: 6,3; QO2: 6,7; QO3: 7,5 e QO4: 6,6. Observa-se que a variação de notas ao longo do período não foi muito grande. Um fato interessante é que, ao contrário do que ocorre em períodos presenciais, não houve uma queda muito acentuada na participação de estudantes entre o início e o final do PLE no que diz respeito aos questionários. Contamos com 1305 estudantes respondendo ao QO1 e 1178 ao QO4, o que representa uma queda de menos de $10 \%$ de participação entre entre um e outro.

\subsection{Provas}

A adaptação das provas para o formato remoto seguramente foi a maior demanda da coordenação da disciplina. As provas de Física 1 no ensino presencial vinham sendo realizadas em esquema parecido com o da realização de vestibulares e do ENEM, com fiscalização, em geral, por pessoas não envolvidas na disciplina e portanto com a exigência de se apresentar no dia da avaliação documentação com foto. A estrutura das provas era híbrida, combinando questões discursivas com múltiplas escolhas. No PLE, a evidente impossibilidade técnica de todos os alunos digitalizarem suas provas e enviarem para 
correção, resultou em provas exclusivamente compostas por questões de múltipla escolha realizadas também por intermédio do Polimoodle, à semelhança dos questionários.

As provas foram disponibilizadas em uma janela de quatro horas, em dias e horários diferentes, como será detalhado a seguir. Uma vez iniciada, os alunos tinham que finalizá-la em um período de três horas corridas. As provas eram compostas de dez questões sequenciais, isto é, uma vez avançando para a questão seguinte não era possível retornar a alguma anterior. Cabe observar que ser sequencial foi alvo do maior número de reclamações por parte dos alunos nesse PLE. Os conteúdos abordados por prova foram os seguintes: P1 - Cinemática, Leis de Newton, Trabalho e energia, P2 - Conservação do momento e colisões, Rotações e momento angular e Dinâmica do corpo rígido, PF - Toda a matéria.

A Figura 10 ilustra as distribuições de notas das três provas. No que se refere a P1, cabe notar que, inicialmente, estavam previstos quatro grupos, cada qual realizando a prova em dias e/ou horários diferentes, de forma a não sobrecarregar a plataforma Polimoodle. Os Grupos 1 e 2 realizaram a prova no mesmo dia, mas em horários diferentes (sendo o Grupo 2 posterior ao 1). Os Grupos 3 e 4 realizaram a prova no dia seguinte, sendo o Grupo 4 posterior ao 3. Como houve uma queda de luz que afetou o servidor Polimoodle durante o primeiro grupo, pouquíssimos alunos conseguiram finalizar a prova (em torno de 10) forçando a realocação do restante dos alunos nos demais grupos. Os alunos que finalizaram a prova no Grupo 1, representados pela cor azul na elaboração do gráfico, devido ao seu baixíssimo número, têm difícil visualização no histograma. Testada a robustez da plataforma Polimoodle quanto ao número de acessos, a P2 e a PF, puderam ser realizadas com apenas dois grupos. Nos dois casos, sendo o segundo grupo em dia seguinte ao primeiro.

Fica evidente, se compararmos os três gráficos, a forma atípica da distribuição das notas da P1. De fato, houve duas grandes diferenças entre a P1 e as outras provas. A primeira refere-se ao número de grupos (dias/horários diferentes). A P1 contando com o dobro de grupos da P2 e PF. A segunda, e mais determinante diferença do nosso ponto de vista, foi o método de elaboração da prova. Na P1, todos os alunos de um mesmo grupo realizavam exatamente a mesma prova - salvo o sorteio de valores numéricos para questões não conceituais (valores "curinga", na terminologia do Polimoodle) - com a mesma sequência de questões. Além disto, as provas dos diferentes grupos eram muito similares. A distribuição peculiar das notas da P1, cujo histograma nos remete a uma exponencial, salvo pela última barra, relativa ao Grupo 4, sugere fortemente que pode ter havido comunicação entre os alunos, apesar do "Termo de confidencialidade", que foi preenchido imediatamente antes da primeira questão, versando sobre o comprometimento de não compartilhar
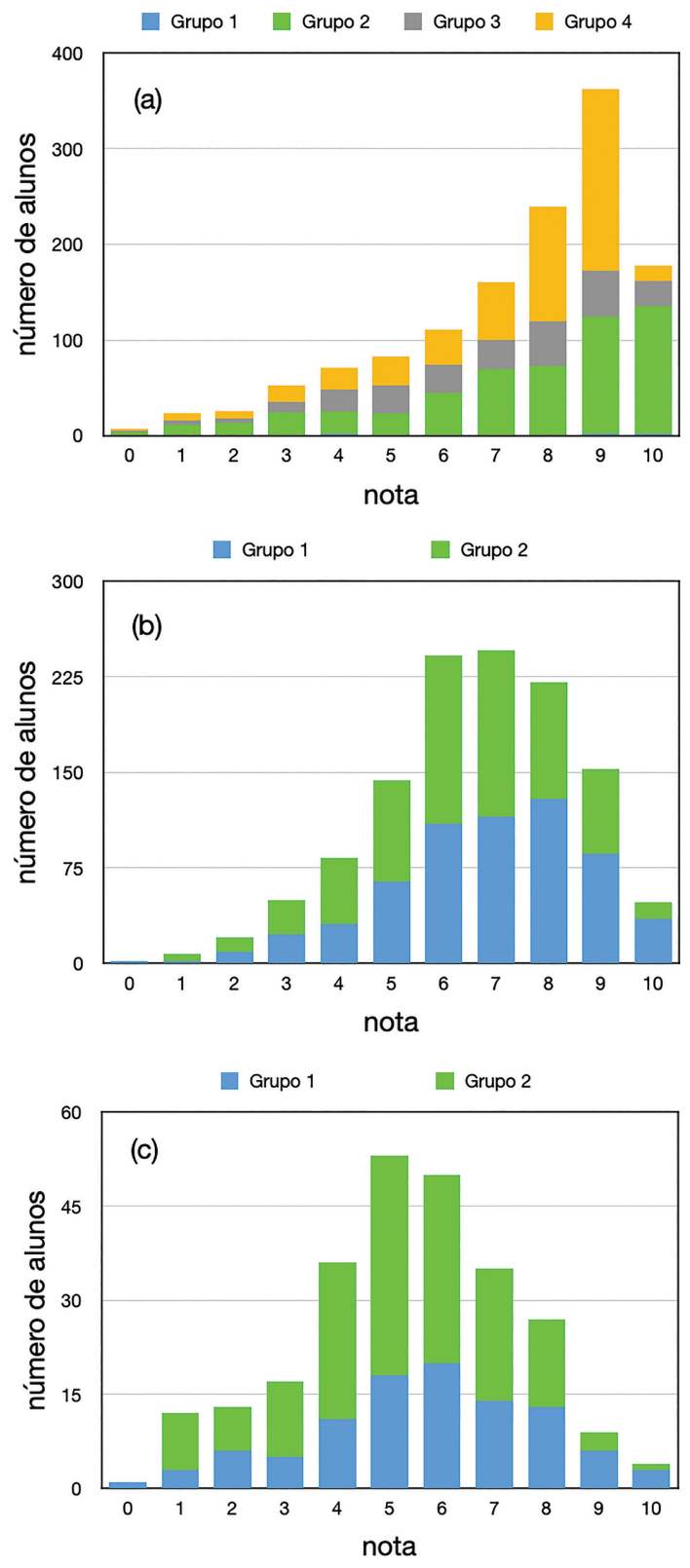

Figura 10: Histogramas da distribuição de notas das provas. (a) Prova 1, (b) Prova 2 e (c) Prova Final (PF). Cada grupo corresponde a um horário e/ou dia diferente de realização da prova. A dificuldade de se visualizar a cor azul no histograma (a) é explicada no texto.

o conteúdo da prova. A última barra relativa ao Grupo 4, pode ser explicada por uma questão cuja figura, embora correta, nos fez concluir posteriormente que induzia o aluno a erro. De fato, apenas $20 \%$ dos alunos acertaram essa questão específica, ao passo que nenhuma das outras teve acerto menor do que $65 \%$.

O fato do histograma de notas da P1 não apresentar a forma esperada - tipicamente gaussiana - nos levou a mudar drasticamente o método de elaboração das provas seguintes. Tanto a P2 quanto a PF fizeram uso de um banco de questões agrupadas por tópicos da disciplina. Cada tópico era composto em média por cinco questões 
diferentes. A prova de um dado aluno, composta por dez questões, consistia de um sorteio aleatório de uma questão dentro de cada tópico. Com este recurso garantíamos que a probabilidade de termos duas provas iguais tendia a zero. De fato, pudemos constatar que estas alterações se mostraram eficazes, uma vez que a distribuição das notas da P2 e da PF claramente se aproximam da forma gaussiana e as médias gerais foram mais compatíveis com o resultado esperado para esta disciplina.

$\mathrm{Na}$ Figura 11 estão indicados os tempos médios de resolução das provas em função das notas. Tirando uma tendência que se observa de um menor tempo de resolução para notas na faixa $0-2$, provavelmente
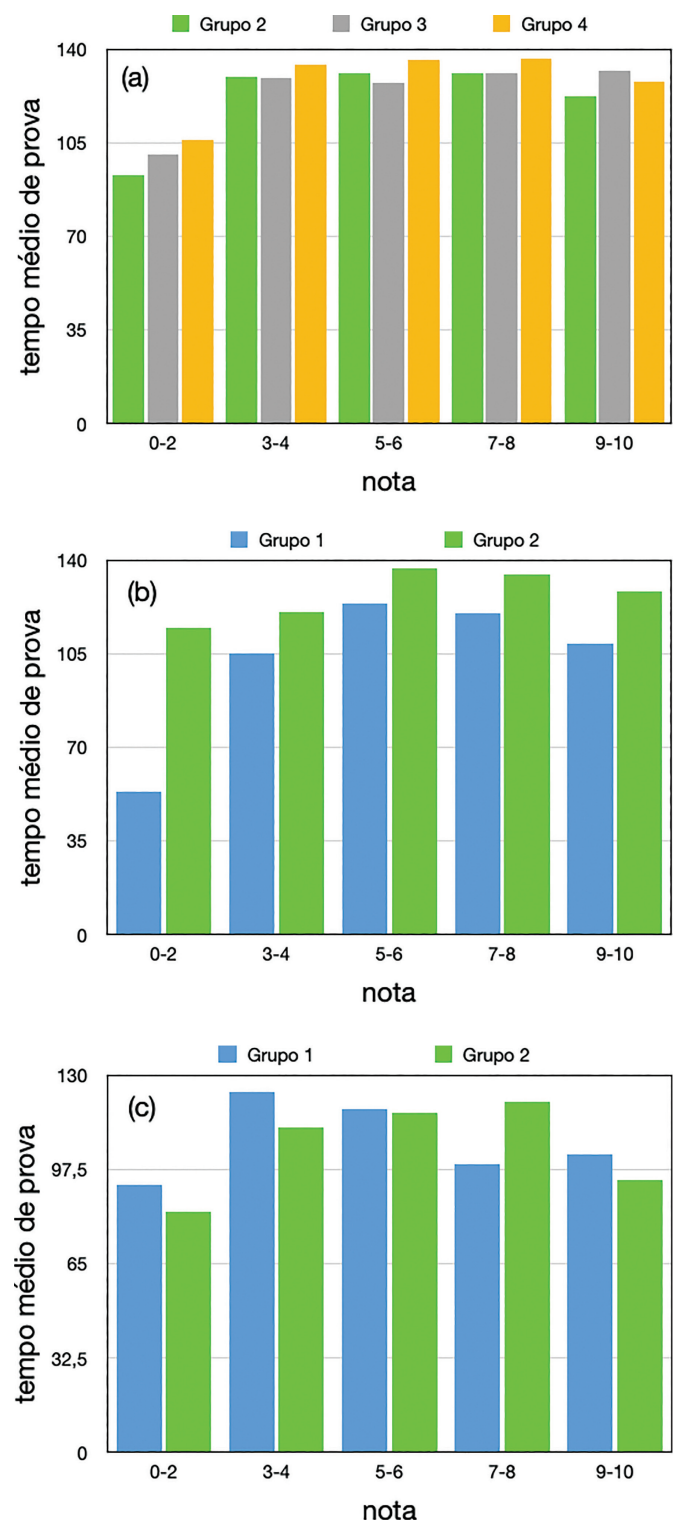

Figura 11: Histogramas com a média do tempo utilizado por faixa de nota. (a) Prova 1, (b) Prova 2 e (c) Prova Final (c). Cada grupo corresponde a um horário e/ou dia diferente de realização da prova.

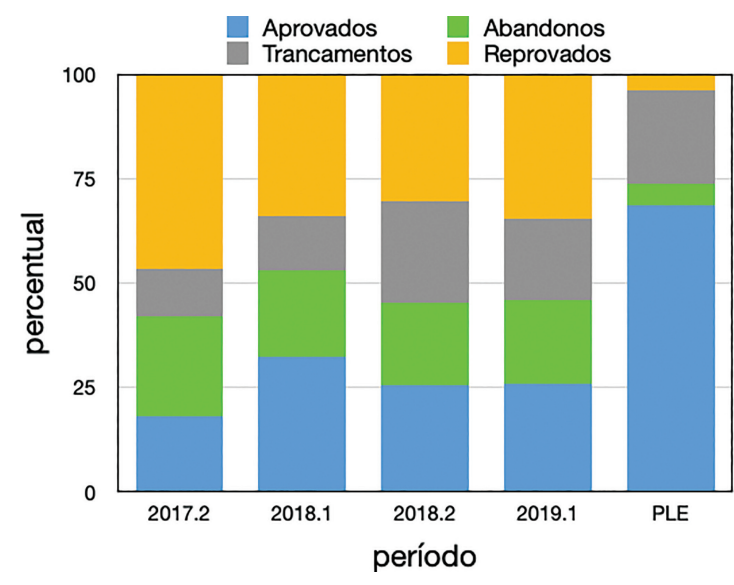

Figura 12: Percentuais de aprovação, abandono, trancamento e reprovação em quatro semestres presenciais e no PLE.

representando alunos que realmente não se prepararam para a prova e a finalizaram mais rapidamente, há pouca variação no tempo médio de realização por faixas de nota.

Na Figura 12 estão indicados os percentuais de aprovação, trancamento, reprovação e abandonos, calculados em relação ao número de inscritos. Em um sistema tão complexo como uma disciplina com mais de 1500 alunos, provenientes de cursos tão diversos, requerse muita cautela para tirar conclusões acerca destes dados. É inegável que o percentual de aprovação no PLE foi bastante superior ao obtido nos últimos períodos presenciais, efeito este também observado em outras Universidades ${ }^{3}$ Aliado à possibilidade de trancamento até depois da última prova realizada, este aumento nas aprovações contribui para os percentuais de $4 \%$ de reprovações e $5 \%$ de abandonos no PLE, significativamente menores que em semestres anteriores. É necessário destacar, no entanto, que a similaridade do percentual de trancamento no PLE, em 2018.2 e em 2019.1, todos da ordem de $20 \%$, é fortuita, visto que medem iniciativas diferentes por parte dos alunos. No PLE o trancamento mede, além dos alunos que por motivos diversos não desejam prosseguir na disciplina, aqueles que, sabendo que estavam reprovados, optaram por remover a reprovação de seu histórico escolar. Temos convicção que, se em semestres anteriores os alunos pudessem trancar a disciplina ao saber que não haviam sido aprovados, grande parte teria eliminado a reprovação por meio do trancamento, como aconteceu no PLE.

A Figura 13 apresenta a avaliação dos alunos a respeito dos itens discutidos nesta seção. A impressão negativa das listas mostrada na figura, corrobora o ponto de maior insatisfação entre os alunos, conforme discutido anteriormente. Os alunos avaliaram majoritariamente de

\footnotetext{
3 Na USP de São Carlos o percentual de aprovação passou de 50\% no ensino presencial, para $70 \%$ no remoto, segundo o prof. Luis Gustavo Marcassa. Na UFF também houve aumento expressivo das aprovações segundo o prof. Lucas Sigaud.
} 


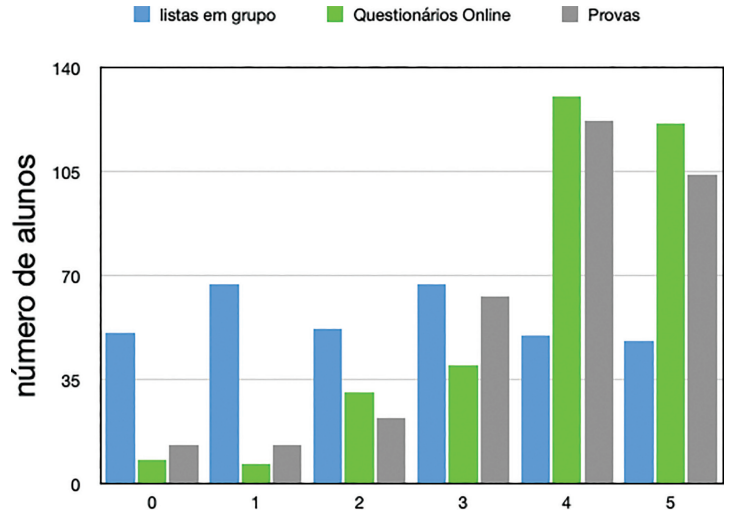

Figura 13: Avaliação dos alunos sobre as listas em grupo, questionários online e provas. 0 : não se aplica; 1 : péssimo, 2 : ruim, 3: regular, 4: bom, 5: ótimo.
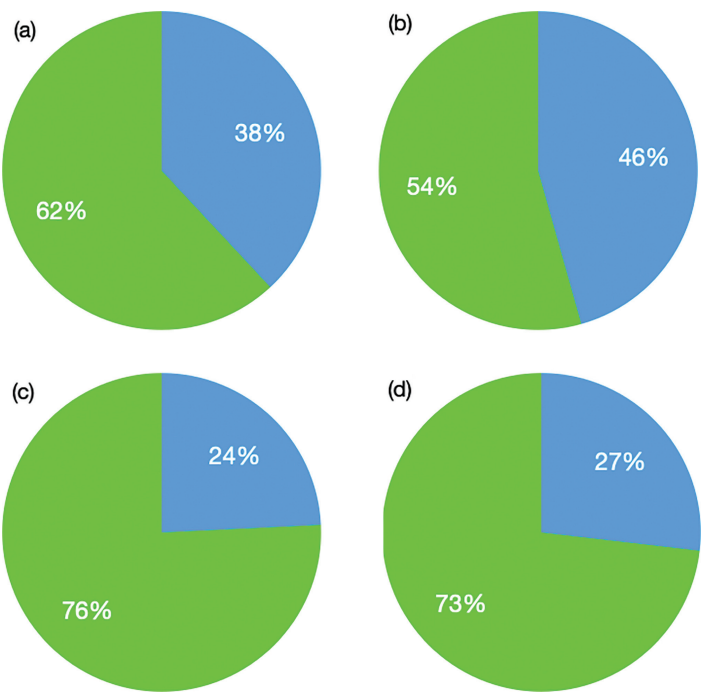

Figura 14: Percentual por gênero de (a) aprovação, (b) trancamentos, (c) reprovação e (d) abandono durante o PLE. Homens em verde e mulheres em azul.

forma positiva os questionários e as provas, a despeito do formato sequencial das mesmas.

Na Figura 14 mostramos os percentuais de aprovações, trancamentos, reprovações e abandonos por gênero. Enquanto os percentuais de aprovação são bastante próximos aos de inscrição por gênero mostrados na Figura 5(a), os outros três são bastante distintos. A Figura 14(b) mostra um percentual de trancamento bastante elevado entre as mulheres, quando comparado ao das inscrições, enquanto as Figuras 14 (c) e (d) mostram que as mulheres abandonaram menos a disciplina e foram menos reprovadas, respectivamente.

\section{Conclusões e Perspectivas Futuras}

Neste artigo detalhamos a formulação completa e o funcionamento da disciplina de Física 1 na UFRJ em formato totalmente remoto utilizando metodologias de ensino ativas. Reportamos a análise estatística de dados extraídos das plataformas utilizadas (Youtube, Wordpress, Zoom e Polimoodle) e ainda a avaliação quantitativa e qualitativa realizada pelos estudantes sobre os diversos aspectos da disciplina. Por se tratar de uma disciplina de uma área exata, onde há historicamente uma predominância masculina, analisamos também a distribuição de gênero entre os inscritos, aprovados, reprovados, trancamentos e abandonos.

A seguir listamos os pontos que gostaríamos de destacar:

- Guia de Estudos - foi um recurso bastante utilizado pelos alunos; a inclusão no mesmo do material considerado essencial, não sobrecarregando os estudantes de informações, possibilitou a organização tanto da divisão do tempo de estudo pelos alunos, quanto do material disponibilizado pelos professores.

- Videoaulas - as estatísticas dos tempos de aulas assistidos indicam claramente que as mesmas devem ser curtas, sugerindo que não devem ultrapassar 15 minutos de duração. O fato das videoaulas estarem disponíveis para serem assistidas de casa, no horário desejado e quantas vezes julgassem necessário, foi ressaltado como um ponto extremamente positivo pelos alunos.

- Aulas síncronas - tanto professores quanto alunos afirmaram que aulas com uma hora de duração não propiciavam tempo de discussão por pares suficiente dentro dos breakout rooms. Com a experiência adquirida ao longo do PLE julgamos que uma hora e meia de duração é próximo do ideal.

- Atendimento aos alunos - dentro da filosofia de instrução por pares e dada a avaliação muito positiva feita pelos estudantes, incentivamos a monitoria por alunos mais adiantados nos diversos cursos que contemplam Física 1 em sua grade horária.

- Provas e questionários - ao propor uma primeira prova com questões únicas por grupo de horário, notamos que a distribuição de notas ficou completamente fora do padrão usual (uma gaussiana). Isso nos levou a adotar bancos de questões como recurso. Alunos de um dado grupo tinham questões sorteadas de um dado repositório. Em grupos de horários diferentes utilizamos questões de bancos distintos. Cada questão de uma dada prova contava com no mínimo quatro opçoes diferentes. O formato aproximadamente gaussiano foi recuperado, o que nos leva a concluir que esse recurso é indispensável.

- Listas em grupo - foi um dos aspectos mais controversos do PLE. Apesar de relatos de outras instituições destacarem listas discursivas em grupo como elementos altamente agregadores e construtivos, recebemos muitas reclamações de alunos, o que nos motivou a abandonar esta prática depois da primeira prova. A alegação dos estudantes foi a 
dificuldade, especialmente de calouros, de formar grupos. Pelo menos no âmbito desta disciplina na UFRJ, onde o número de alunos é muito elevado, ainda precisamos elaborar melhor este ponto, de forma a criar mecanismos eficientes de interação.

A seguir relacionamos algumas iniciativas que iremos incorporar nos próximos semestres.

- Vídeos com resoluções de exercícios - os alunos solicitaram que disponibilizássemos vídeos com a resolução comentada de alguns exercícios relevantes.

- Vídeos com demonstrações de experimentos - o Laboratório Didático do Instituto de Física (LADIF) ${ }^{4}$ conta com uma série de experimentos e demonstrações que os professores levavam regularmente para sala de aula durante os semestres presenciais. Estas demonstrações instigam a curiosidade e auxiliam na compreensão dos conceitos abordados. Vamos incorporar esses vídeos ao material disponibilizado aos estudantes. Os vídeos já gravados estão acessíveis ao público em geral.

- Aulas de apoio - algumas turmas têm andamento mais lento que outras. Isso se dá porque cursos diferentes têm notas de corte muito diferentes para a entrada na UFRJ, assim alunos provenientes de instituições com ensino muito díspar ingressam simultaneamente em Física 1. Alunos com menos base necessitam de apoio desde o começo do semestre para reduzir suas deficiências de formação.

- Turmas com metodologia tradicional - pretendemos organizar turmas de Física 1 com aulas expositivas para comparar o desempenho dos alunos com metodologias distintas.

- Novas perguntas no questionário - iremos expandir o questionário de avaliação da disciplina apresentado aos alunos para incluir questões sobre o perfil socioeconômico dos mesmos, sobre o tempo de duração da videoaula, bem como sobre sua a percepção em relação ao aprendizado por meio de metodologias ativas.

Para finalizar gostaríamos de compartilhar nossa reflexão, contrariando as expectativas iniciais de muitos, de que o formato remoto possa promover uma redução das desigualdades sociais na educação. A UFRJ proveu acesso à internet, por meio de compra de chips de celular e equipamentos para estudantes de baixa renda. Uma vez garantido o acesso remoto por parte dos alunos, cabe investigar se a economia de tempo, dinheiro em transporte e alimentação e redução de estresse devido à exposição à violência urbana - mais acentuada para alunos que moram nas periferias - de fato, podem ser determinantes para que alunos menos favorecidos financeiramente tenham mais disposição para aprender

\footnotetext{
4 https://ladif.if.ufrj.br/
}

e se dedicar aos estudos, resultando em um melhor desempenho.

Com esse artigo esperamos contribuir para a discussão do tema do ensino remoto com aprendizagem ativa em termos nacionais 14 e globais através de comparações com o resultado de outras instituições e assim aperfeiçoar ainda mais esta nova metodologia. Mais especificamente, o ensino remoto como única forma de ministrar cursos durante a pandemia certamente dará origem a inúmeros artigos de avaliação e esperamos estar abrindo caminho para que outras instituições se sintam estimuladas para este fim. À época do retorno às aulas presenciais, muito do material remoto utilizado será aproveitado, senão sua totalidade, de forma que este tipo de avaliação é de suma importância no futuro.

\section{Agradecimentos}

A todos os professores que fizeram parte da equipe de Física 1 durante o PLE: Anibal Ramalho, Gabriela Barreto Lemos, Joaquim Lopes Neto, Marcello Barbosa da Silva Neto, Róbinson Acosta e Sérgio Eduardo de Carvalho Eyer Joras e aos alunos de pós-graduação em prática de ensino Ayrton da Cruz Pereira do Nascimento, Gyell Gonçalves de Matos e Lucas Oliveira Lima. A Rodrigo Lage Sacramento e Ribamar Rondon de Rezende dos Reis por nos enviarem os dados de Física 1 de 2019. À Maria Carolina Aguiar e André de Pinho Vieira por compartilharem informações sobre os cursos presenciais de Física 1 na UFMG e na USP com o uso de metodologia de sala de aula invertida e instruções por pares. A Luis Gustavo Marcassa, Pedro Holanda e Gabriel Teixeira Landi pela solidariedade e gentileza na troca de informações sobre o ensino de Física 1 remoto em suas instituições. Finalmente, a Jorge Sá Martins pelas discussões inspiradoras sobre instrução por pares.

\section{Referências}

[1] E.J. Theobald, M.J. Hill, E. Tran, S. Agrawal, E.N. Arroyo, S. Behling, N. Chambwe, D.L. Cintrón, J.D. Cooper, G. Dunster et al., PNAS 117, 6476 (2020).

[2] J. Bergmann e A. Sams, CSE 17, 26 (2013/2014).

[3] Eric Mazur, Peer Instruction: A User's Manual (Prentice Hall, inc, 1997).

[4] E. Mazur, Principles \& Practice of Physics (Pearson Education, Inc, 2015).

[5] P. Zhang, L. Ding, e E. Mazur, Phys. Rev. Phys. Educ. Res. 113, 010104 (2017).

[6] C.H. Crouch e E. Mazur, Am. J. Phys. 69, 969 (2001).

[7] I.S. Araujo e E. Mazur, Cad. Bras. Ens. Fís. 30, 362 (2013).

[8] S. Freeman, S.L. Eddy, M. McDonough, M.K. Smith, N. Okoroafor, H. Jordt e M.P. Wenderoth, PNAS 111, 8410 (2014).

[9] C.E. Wieman, Large-scale comparison of science teaching methods sends clear message, PNAS 111, 8319 (2014). 
[10] https://fisica1ifufrj.wordpress.com/

[11] https://www.youtube.com/channel/UCMsiE8BVV1U yqEJiwP6kP5A

[12] R. Berg, A. Brand, J. Grant, J.S. Kirk e T. Zimmerman, Online Classroom 14, 5 (2014).

[13] P.J. Guo, J. Kim e R. Rubin, em $L @ S$ '14: Proceedings of the first ACM conference on Learning@ scale conference (Atlanta, 2014).

[14] J.A. Barros, J. Remold, G.S.F. Silva e J.R. Tagliati, Revista Brasileira de Ensino de Física 26, 63 (2004). 